\title{
Lean-burn CNG engine with ignition chamber: from the idea to a running engine
}

Current and further developing $\mathrm{CO}_{2}$ - and emission regulations worldwide and the competition to full electric mobility deliver a challenge for internal combustion engines in general. A state of the art solution is the use of natural gas mainly contending methane to reduce $\mathrm{CO}_{2}$ significantly and to offer lowest emission levels. The EU-funded project GasOn developed engine concepts to fully exploit the advantages of CNG. This article describes the development of an innovative, monovalent engine dedicated to Compressed Natural Gas $(C N G)$ and characterised by the lean burn concept and the innovative pre-chamber combustion.

Key words: CNG, scavenged prechamber, lean combustion, ignition system, efficiency

\section{Introduction}

CNG engines offer a $\mathrm{CO}_{2}$ reduction level of above $20 \%$ compared to diesel and gasoline engines due to the chemical properties. Methane, the main content of natural gas, offers a higher $\mathrm{H} / \mathrm{C}$-ratio than the hydrocarbon molecules of Diesel and gasoline. An additional potential for $\mathrm{CO}_{2-}$ reduction is the possibility of producing renewable methane so a $\mathrm{CNG}$ powertrain can become $\mathrm{CO}_{2}$-neutral.

Current CNG-engines are derived from gasoline engines and are limited by boundaries determined by the bivalent concept. Such a compromise is a low compression ratio, that is usually chosen for the use of gasoline and does not fully exploit the potential of the highly knock resistant CNG. Additionally a stoichiometric combustion is state of the art due to exhaust gas aftertreatment technology. A lean combustion offers further potential to increase efficiency and to reduce $\mathrm{CO}_{2}$ emissions.

The objective of the described engine concept of GasOn is to fully exploit the efficiency potential of CNG in a dedicated engine, including a high compression ratio $(\varepsilon>14)$ and lean burn $(\lambda=2)$. An enabling technology for lean combustion is the use of a prechamber, which is known from large bore engines, used for example by MAN Energy Solutions. The prechamber can be interpreted as a highly powerful ignition system like a Diesel pilot injection but running on the same fuel like the main combustion. It offers high energy ignition for the lean combustion without adding a second type of fuel.

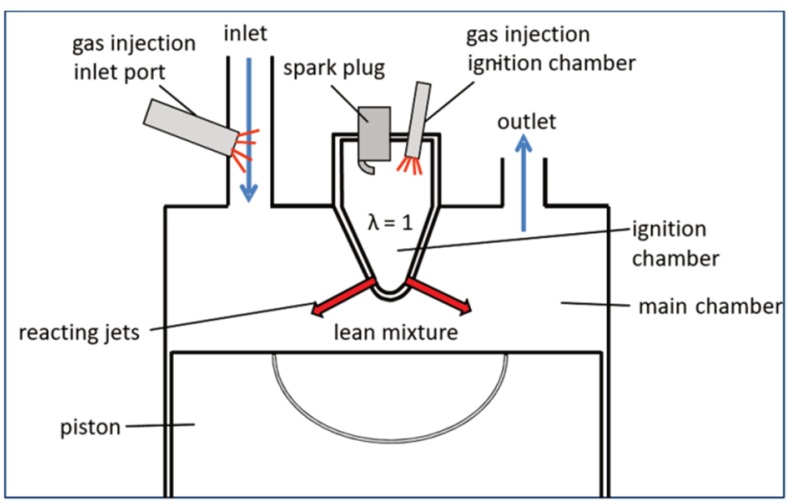

Fig. 1. CNG combustion system of lean burn with prechamber
As shown in Fig. 1 the combustion is divided into two chambers. The main chamber is supplied with the lean mix of CNG and air. After the compression stroke parts of this mixture are pressed into the prechamber. The lean mix cannot be safely ignited under the high pressure of compression. Therefore, a small quantity of pure CNG is dosed into the prechamber via a separate dosing system and creates an approximately stoichiometric mixture inside the prechamber. This mixture can be ignited by the spark plug and the combustion process in the prechamber creates highly energetic flame jets exiting into the main combustion chamber. These flame jets are able to capture the content of the main combustion chamber fast and nearly completely which results in a stable combustion process.

The introduction of this combustion system into a $2 \mathrm{~L}$ class engine size creates several challenges, which need to be addressed. As a general figure the prechamber system needs to be only $1 / 3$ up to $1 / 5$ of the size of the known components from the large bore engines. These challenges and the related technical solutions are described in the following chapters.

\section{Base engine}

One of the most important aspects of the new combustion system is the increased compression ratio compared to a gasoline engine. The final value is not fixed at the beginning of the project and a variation of different compression ratios is scheduled. The envisaged range of compression ratios reaches up to eps $=15.5$, which leads to expected cylinder peak pressures far beyond the mechanical limit of adequate gasoline engines. Typical peak pressure limits of dual fuel engines are in the range of 100 to 120 bar, while the new combustion system might deliver 150bar or more. To ensure the highest possible mechanical robustness to the project it has been decided to use the Volkswagen EA288 VN diesel-engine as a base engine for the lean burn prechamber combustion system. Diesel engines of the 2.01 class [3] can typically withstand cylinder pressures up to 200 bar and are therefore perfectly suited for the monovalent $\mathrm{CNG}$ combustion.

\section{Design challenges}

The development of the combustion system in the decided Diesel engine offered (amongst others) the following challenges: 
- downscaling and package of the prechamber and related components into the cylinder head

- design of the prechamber (shape, nozzles etc.)

- cooling and sealing concept

- piston shape

- dosing system to scavenge the prechamber

The following chapter will describe the mentioned challenges and the chosen technical solutions.

\subsection{Package, sealing and cooling}

Prechambers are known mainly from gasoline race engines and from large bore Diesel engines. Both concepts offer easier package situations due to an open combustion chamber with angled valves (gasoline engine) or by large bore diameters (industrial engines) which allow for an comparable easy integration of the prechamber and it's necessary components. The chosen Diesel engine mainly offers the room formerly used by the high pressure Diesel injector in the centre of the cylinder head. In between the vertically oriented valves and the related narrow space between the camshafts it is not possible to integrate components with a diameter much greater than the Diesel injector. In a tubular space of appr. $30 \mathrm{~mm}$ all components have to be integrated: the prechamber, the top lid of the prechamber, the check valve, the CNG supply of the dosing system, a pressure sensor, the spark plug and the ignition coil. Being an experimental engine with the plan to test numerous variations of the prechamber it is also important to create a design that offers sufficient serviceability. It is important to be able to change single components without disassembling the cylinder head.

To address these targets all components are made modular and are clamped into the cylinder head by a tubular locking nut as shown in Fig. 2.

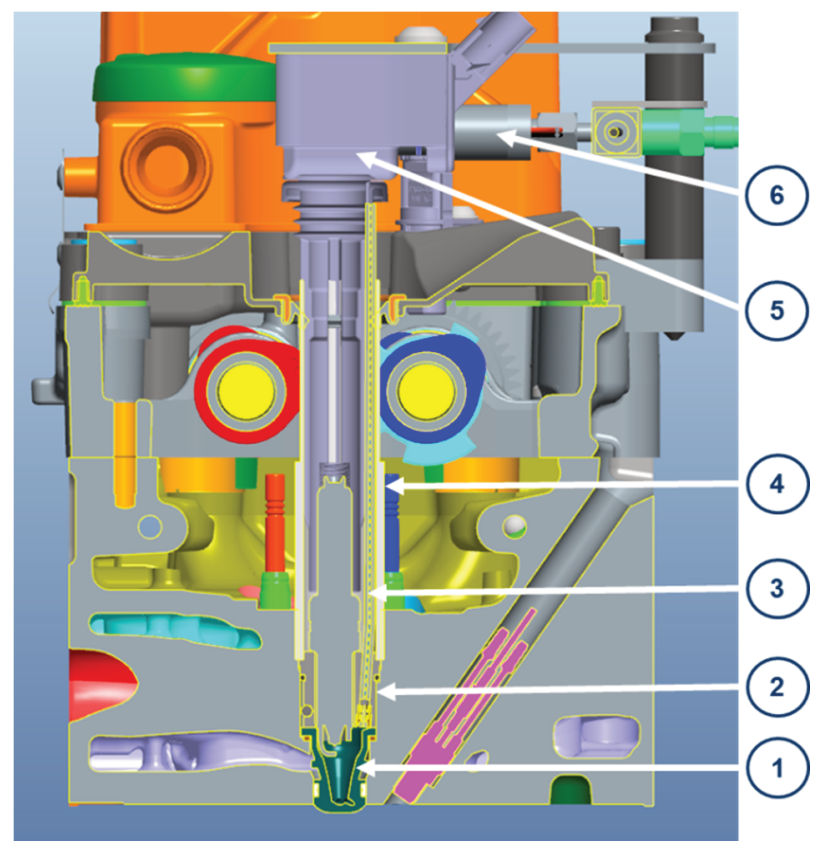

Fig. 2. Section view through cylinder head of GasOn engine with prechamber

The main part of the assembly is the prechamber (1), which is made from a heat resistant steel. The chamber is closed by an aluminium top lid (2), which is carrying the spark plug, a pressure sensor, a check valve and the cannulary tube of the dosing system (3). All parts are clamped onto the cylinder head by a locking nut (4). Outside of the shown tubular space the plug top ignition coil (5) and the dosing system (6) are located.

This layout fits smoothly in between the camshafts and still allows for an comparatively easy access to the named components. The locking nut is a multifunctional part as it also separates the oiled area of the cylinder head from the dry area outside to ensure an oil free operation of the ignition system.
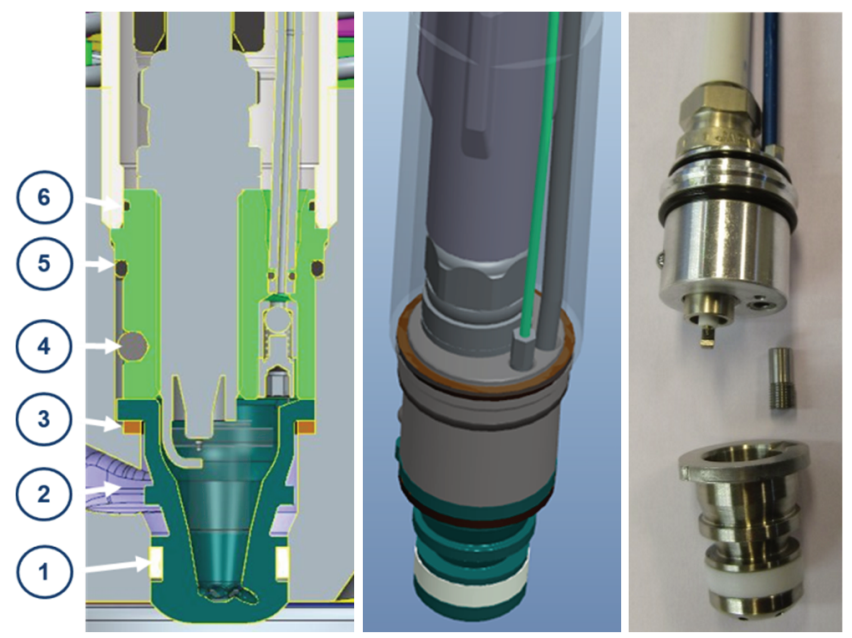

Fig. 3. Section view through prechamber assembly, 3D view and photo of hardware

The sealing concept needs to address all three media coolant, ambient air and oil as well as the hot combustion gases. The prechamber is located in the coolant (2) of the engine to avoid overheating and to allow for a robust engine for the scheduled tests. The sealing between the water area and the main combustion chamber is done by a teflon ring (1). The sealing between the water area and the prechamber area is addressed by a copper ring (3), which is loaded with pressure by the locking nut. With the O-Rings (5) and (6) the sealing towards the oil area and the ambient air area is achieved.

One aim is a good serviceability, which includes an easy change of the spark plug. For the top lid being a rotationally symmetrical part which would turn at the moment when the sparkplug should be screwed in or out, a device is required to avoid a rotation of the lid and also to ensure a defined rotational position. This device is a ball (4) located in the hutch of the lid engaging a groove in the cylinder head.

\subsection{Design of the prechamber}

The design of the prechamber is determined by various boundaries and parameters. The first boundary is the available space, which is limited by the design of the base engine (valve position) hence defining the maximum diameter. The other aspect is the functional geometry to create an appropriate gas motion for a fast and efficient combustion in both, the prechamber and in the main combustion chamber. 
To define suitable geometries numerous CFD simulations have been performed [2] and numerous versions have been built and tested in hardware. The first parameter is the internal shape. Three shapes and accordingly three different chamber volumes between 1.4 and $2.2 \mathrm{~cm}^{3}$ have been designed.
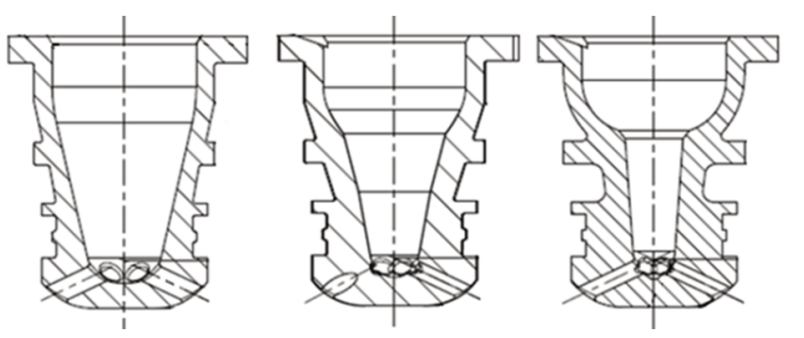

Fig. 4. Three internal shapes with $2.2 / 1.8 / 1.4 \mathrm{~cm}^{3}$ volume

The shape of the prechamber is defined by the target to create best possible conditions at the spark plug for a safe and fast ignition. A nearly stoichiometric mixture shall be combined with a certain turbulent kinetic energy (TKE) level [5]. The developed shapes shown in Fig. 4 offer different amounts of a bottle-like section. This shape supports swirl and TKE creation and is a proper solution to adjust the internal volume while allowing for a robust flow structure.
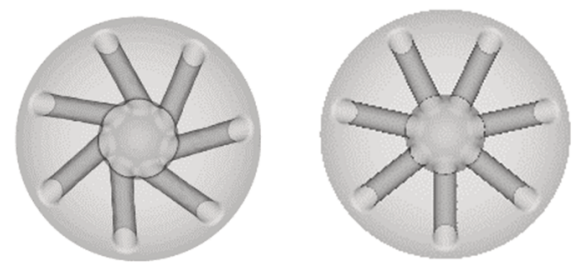

Fig. 5. Orientation of the nozzles: tangential (left) and radial (right)

The internal volume is a parameter that defines the amount of energy, which is supplied by the burned mixture in the prechamber as ignition system for the lean mixture in the main combustion chamber. A bigger volume offers more energy and offers a higher combustion robustness at very lean conditions of above lambda $=1.8$. In terms of efficiency a smaller volume is welcome.

A key parameter of the prechamber is the design and orientation of the nozzles. The varied parameters within the project are the nozzle diameter, the quantity and the orientation. The diameter is interesting in terms of creating flame quenching when the flame/reacting gases are moving through the nozzle. Diameters much smaller than $1 \mathrm{~mm}$ are discussed to result in flame quenching phenomena. In combination with the quantity of nozzles the diameter determines the cross section between prechamber and main combustion chamber. A higher cross section leads to lower pressure gradients, which can influence the complex combustion process. The tested nozzle diameters have been varied between 1,0 and $2,0 \mathrm{~mm}$. The third parameter is the nozzle orientation. An aspect of the orientation is to place them in a radial or tangential orientation as shown in Fig. 5. Using the radial orientation does not add or create any swirl, neither in the prechamber during compression stroke nor in the main combustion chamber during combustion. Swirl can be achieved with tangential nozzles, which can be oriented in the same or in the opposite direction of the swirl flow of the main combustion chamber. A higher significance of the nozzle orientation can be seen inside the prechamber, where the flow structure is totally different when comparing radial with tangential nozzles. While the tangential orientation leads to a controlled swirl structure the radial orientation leads to a straight flow structure. Both can lead to the envisaged conditions at the spark plug.

A CFD comparison in Fig. 6 shows the different character of the flow structure hence the relevance of the nozzle orientation. The velocity distribution of the flow shows a totally different character if changed from tangential to radial nozzles. While the first one creates a clear swirl inside the prechamber with the highest velocities at the outside of the prechamber the radial nozzles create a high velocity field in the core of the prechamber.

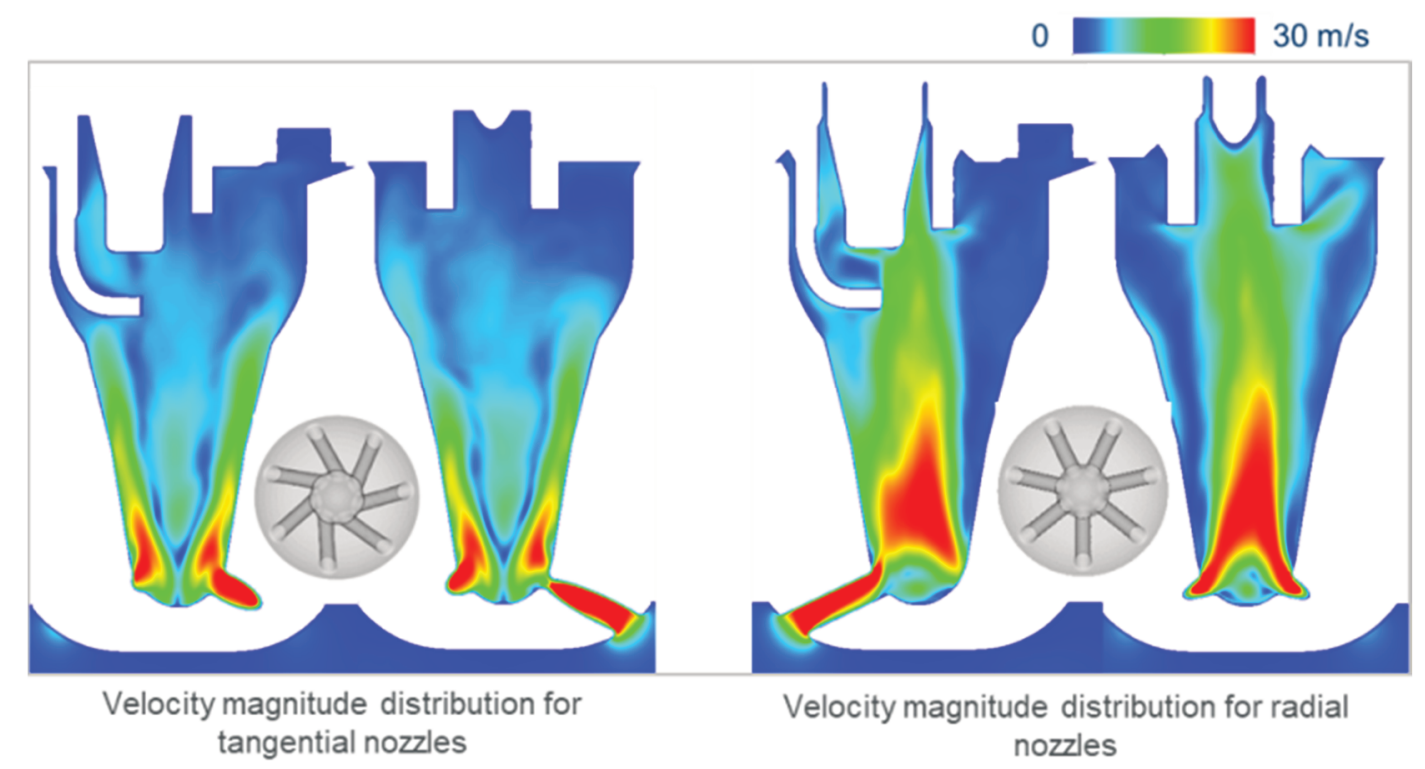

Fig. 6. Flow structure inside the prechamber during compression stroke depending on nozzle orientation 
On the basis of the results of further CFD simulations a number of more than 10 different types of prechamber have been designed, produced and tested. This also includes designs with additional nozzles, which are oriented nearly vertically pointing down into the main combustion chamber as shown in Fig. 7. The relevance of this feature is obvious when considering the piston and its bowl as another design parameter for the combustion process.

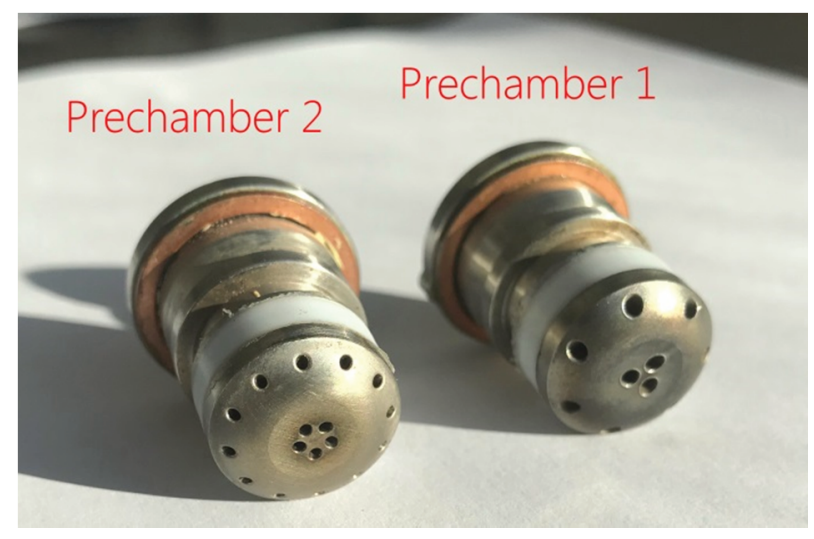

Fig. 7. Two different samples of prechambers with additional nozzles [4]

\subsection{Design of the piston}

In Diesel engines typically the Diesel injector and it's injection coils are matched to the piston bowl to create the best possible combustion in terms of efficiency and emissions. The same approach is necessary for the investigated CNG lean burn prechamber combustion process, which creates flame jets comparable to those of a Diesel injection. Therefore the piston has been designed with different bowls for two purposes: variation of compression ratio between 13.5 and 15.5 as well as matching the bowl with the nozzles of the prechamber. In this article the matching of piston and prechamber is described. All designs of piston and prechamber are created based on CFD simulations [2].

The base design of the piston was a hemispheric bowl as shown in the Fig. 8. It has been tested as a reference in combination with a standard spark plug ignition in the main chamber without any prechamber. This layout delivered the baseline in terms of lean limits in a standard concept. In the next step this hemispheric design has been combined with a set of prechambers containing one array of nozzles pointing nearly horizontally into the main combustion chamber, but varied in terms of orientation, quantity and diameter. It is obvious that the flat array of flame jets does not capture the CNG-air-mixture inside the hemispheric piston bowl completely so the optimisation started in two ways: adding additional nozzles pointing downwards and creating a piston bowl with a omega-shape.

Finally two families of pistons have been designed. The first one are the hemispheric pistons, which adds a version with a rounded edge and a smaller squish area to the shown base design. The second family are the pistons with an omega shape, which are also designed with a sharp and a rounded shape at the squish area. The designs have then been tested in combination with different prechambers. The main concepts are shown in Fig. 9.

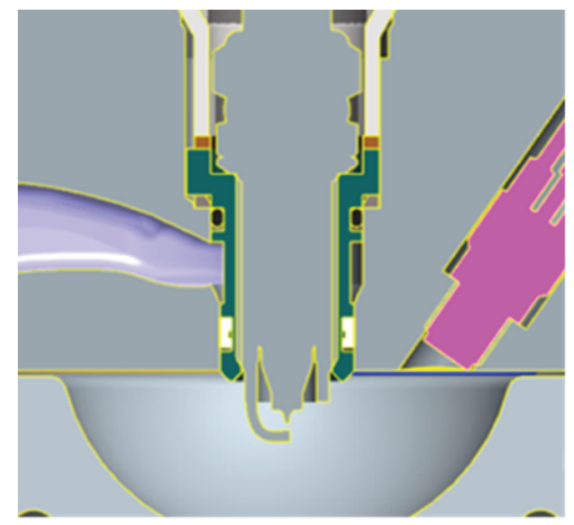

Engine \#1: spark plug

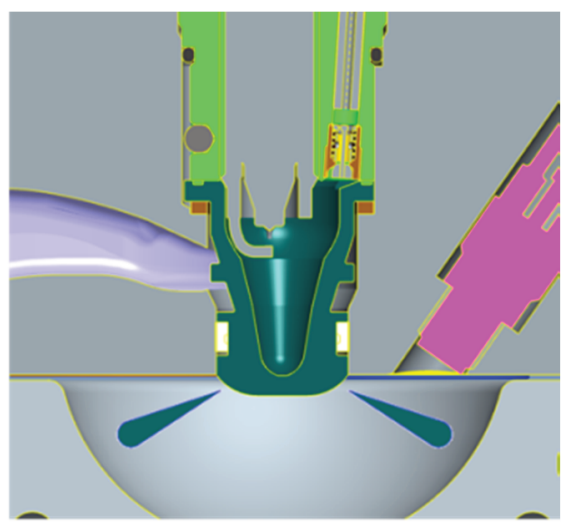

Engine \#2: prechamber

Fig. 8. Hemispheric piston bowl combined with standard spark plug and with prechamber

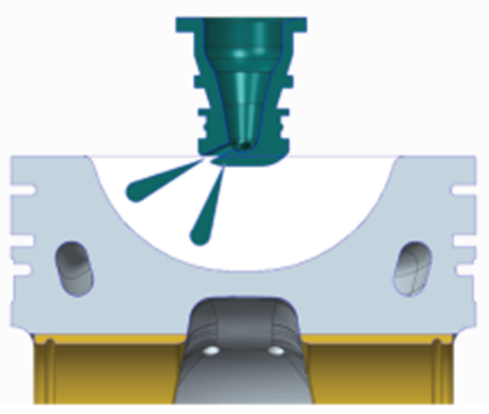

Hemi

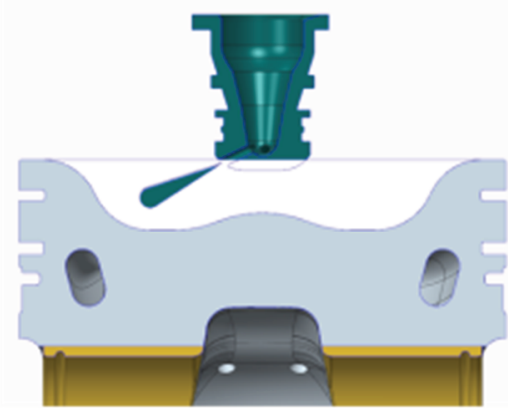

Omega rounded

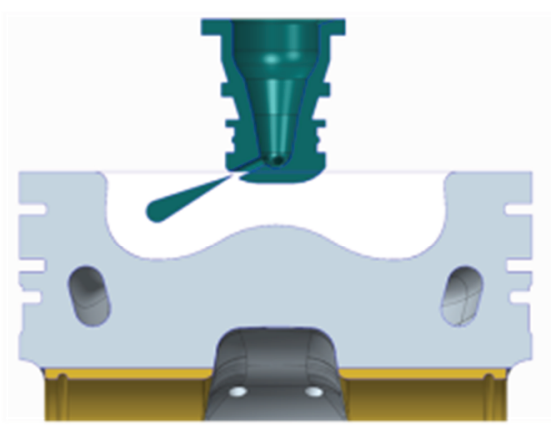

Omega $\mathrm{H}$

Fig. 9. Hemispheric and omega shaped piston bowls in combination with two different types of nozzle orientation 


\subsection{Dosing system}

Prechambers can work in two different operating modes, a passive and an active one. Passive operation means that no scavenging is actively done within the prechamber so the mixing inside it relies passively on the gas dynamics of fresh and residual components. In GasOn it is scheduled to design an active prechamber, which allows for a dedicated supply of small amounts of CNG directly into the prechamber. This is done to enable the engine for the very lean mix combustion of up to lambda 2 .

A general layout of the CNG supply to the engine showing the two different pathways of CNG to the prechamber or the main combustion chamber is shown in the Fig. 10.

To realise a dosing system some technical requirements need to be addressed. The first one is the ability of injecting very small CNG quantities of less than $1 \mathrm{mg}$ per stroke. Additionally the system has to be packaged outside of the cylinder head because of the expected size of the injector. After first attempt with an pressure supported electromagnetic valve, which came out to be unreliable and missing the required precision and repeatability from stroke to stroke, a new design had to be created. The dosing system is finally based on Bosch NGI2 injectors, which are integrated in a throttling system and connected to the prechamber via a cannulary tube. All involved components between injector and prechamber are designed to minimise the involved volume to increase controllability and precision. 1D flow simuation and basic testing helped to find the final and reliable solution.

The dosing system is a low pressure system designed for pressures up to 10 bar as known from usual CNG systems feeding the injectors. This is required for the reason of creating very small mass flows per injection and for the simplicity and robustness of the system.

To safe the system from the high pressures inside the combustion chambers the engine needs to be equipped with check valves.

\subsection{Check valve}

An important element of the dosing system and direct interface to the prechamber is the check valve. It is located directly at the entrance of the dosing system into the prechamber and is important to avoid the high combustion pressures to affect the dosing system.

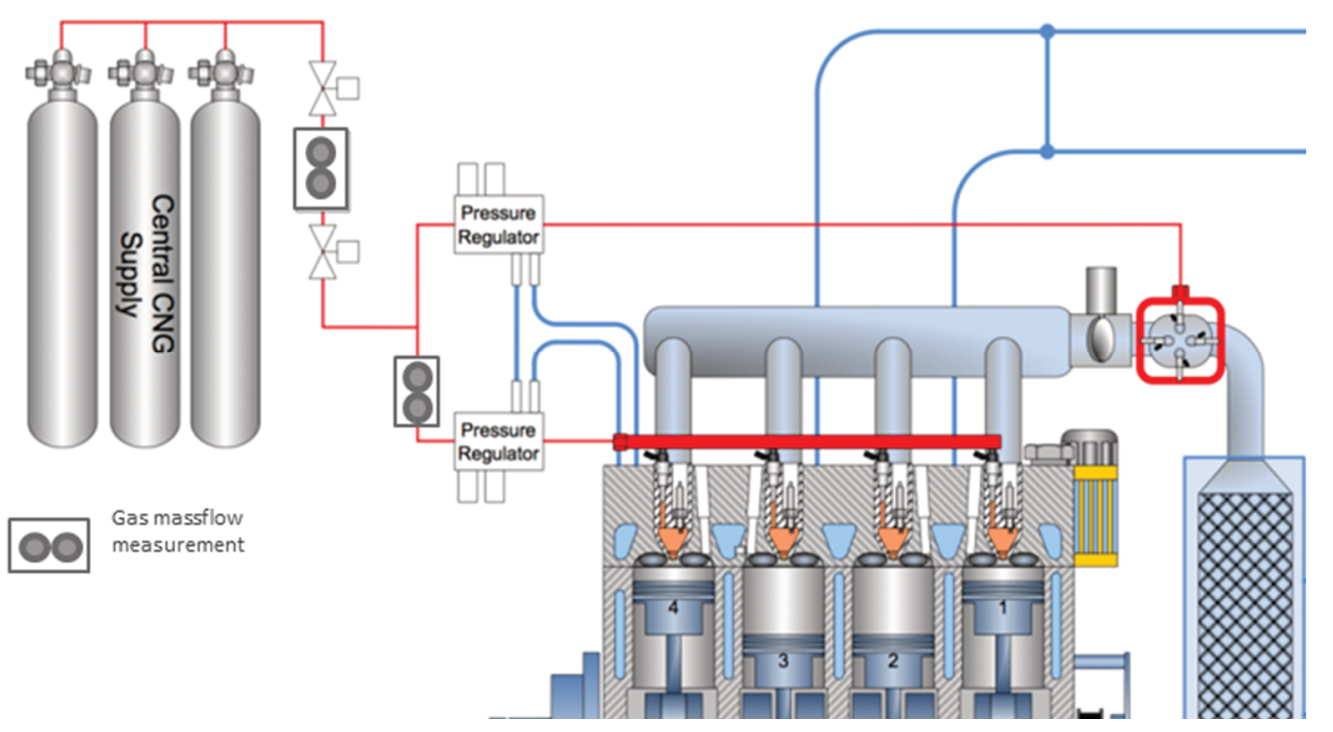

Fig. 10. Schematic overview of the CNG supply of the GasOn engine showing the supply of the main combustion chamber and the separate supply for the prechamber
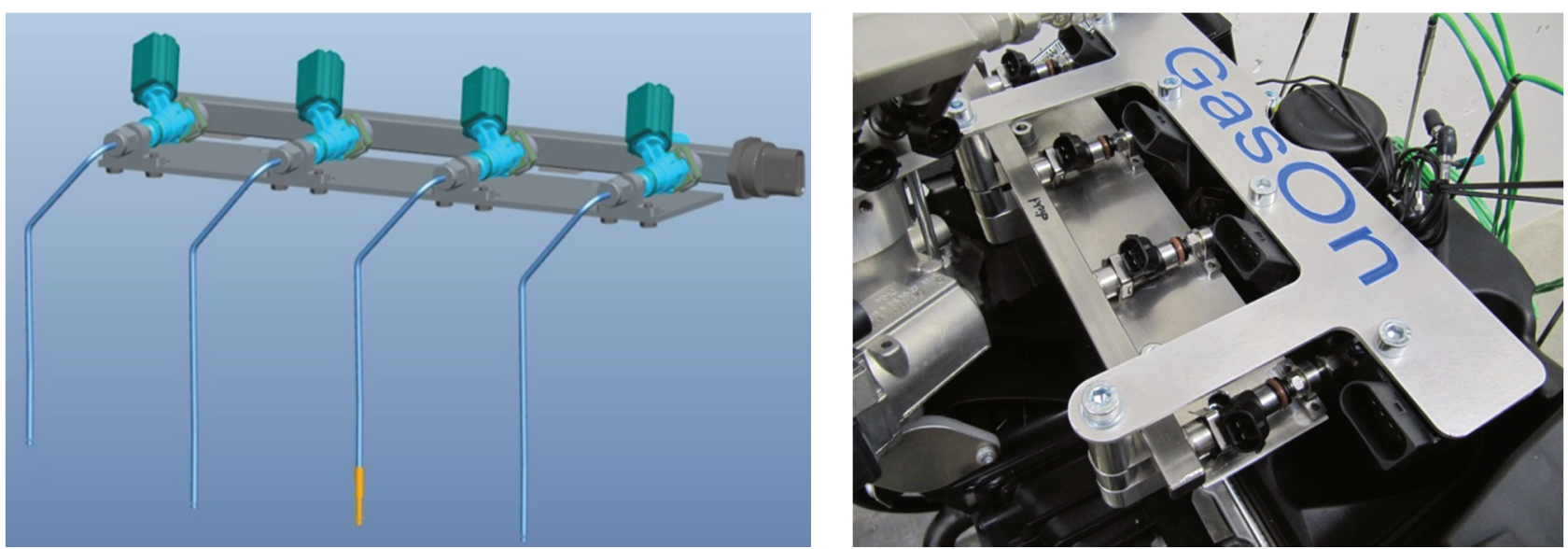

Fig. 11. Dosing system for active (scavenged) prechamber operation 
The check valve needs to be designed from scratch because there is no suitable system available in the market. The valve needs to fit into the diameter of $3.5 \mathrm{~mm}$, has to be temperature resistant and should not offer unnecessary dead volume as a HC-trap. A first design has been built, which was perfect in terms of minimum dead volume, but it turned out to be too complex to be manufactured inside suitable tolerances. As a consequence the variation between the built samples was too big.

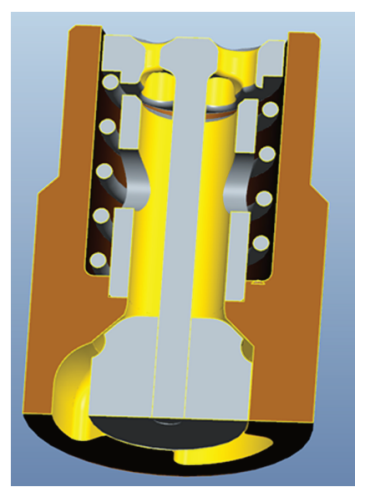

Fig. 12. Check valve, first version with minimised dead volume

To optimise this component, several design steps have been performed as shown below. A key to success was to separate the internals of the valve to avoid risky and hardly controllable welding steps and to create simple, producible parts that are assembled to a valve system in the top lid of the prechamber.
The integration of the check valve in the prechamber top lid is shown in Fig. 14.

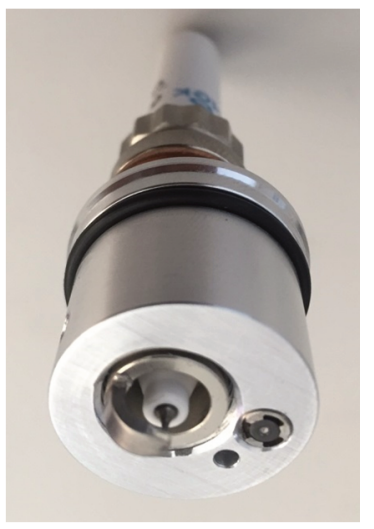

Fig. 14. Assembly of check valve (design 1) into prechamber top lid

\section{Results}

The described components including some more unmentioned design work assembled to a new engine, dedicated to run on $\mathrm{CNG}$ only and offering a lean prechamber combustion process. Not touched in this article are the changes to the piston rings to address the different pressure situation of the throttled operation (the Diesel engine is made for unthrottled operation), the modified exhaust manifold and turbocharger, the gasmixer for the CNG-supply to the main combustion chamber and of course the use of special components in the valve train able to run on $\mathrm{CNG}$.

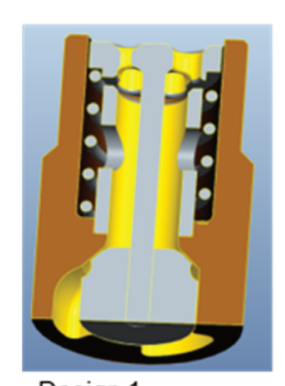

Design 1

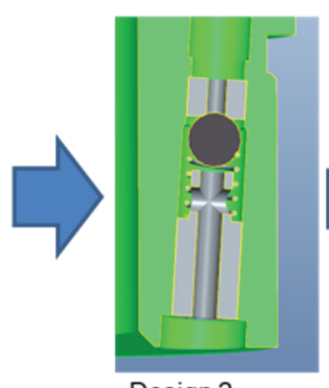

Design 2

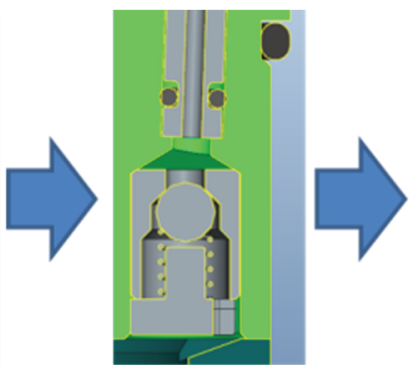

Design 3

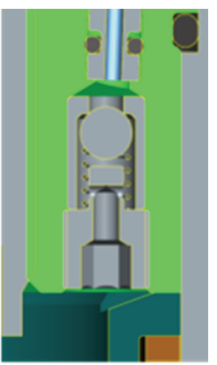

Design 4

Fig. 13. Evolution of the check valve to the final version
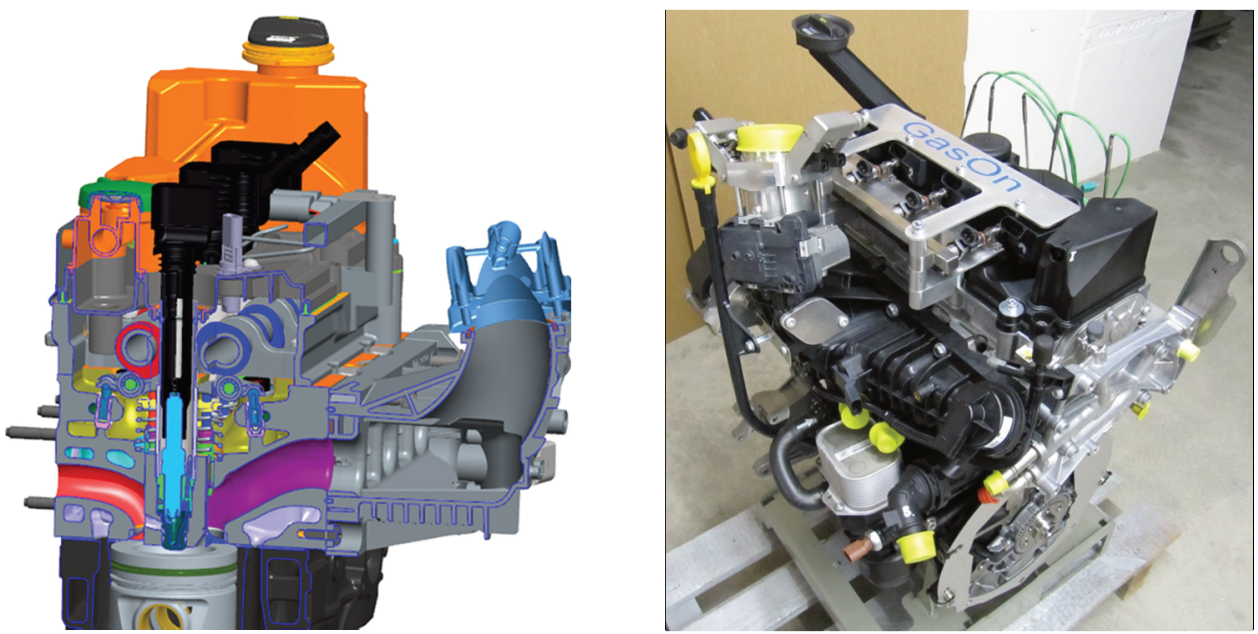

Fig. 15. Section view and photo of GasOn engine 
The engines could be driven as planned from the beginning without major problems which was a success for the design and engineering effort creating this engine. The prechamber system is working, the lambda limit for the scavenged operation is above 2 , the dosing system is working precisely with very low quantities and all efforts lead to a very promising number: the engine reached a best tested efficiency at lambda 1.7 of more than $44 \%$.

\section{Conclusions}

In this article, the main challenges for designing a prechamber system for the selected 2.0L Diesel engine have been described and appropriate solutions have been realised. The focus is to find a package and a functional geometry (shape of prechamber, nozzle, piston) at the same time. To achieve the project objective, extensive use of CFD work was required.
An initial question of the project was, if the prechamber combustion system from large bore engines can be applied to much smaller engines as well due to different sizes, diameters, speeds and other parameters. GasOn made a first step of research work in this direction and showed, that the lean prechamber combustion can be applied with a very promising result of working hardware, high combustion efficiency, good combustion robustness and high process controllability.

\section{Acknowledgements}

The work presented is part of the Horzon2020 project "GasOn". This project has received funding from the European Union's Horizon 2020 research and innovation programme under grant agreement No 652816.

\section{Bibliography}

[1] BOLLA, M. et al. Numerical study of turbulence and fuelair mixing within a scavenged pre-chamber using RANS and LES. Submitted to SAE World Congress and Exhibition. Manuscript no: 19PFL-0664.

[2] LUCAS, G., TALLU, G., WEIBNER, M. CFD-based development of an ignition chamber for a lean and high efficient CNG combustion. THIESEL 2018 Conf. Thermo- Fluid Dyn. Process. Direct Inject. Engines High-Pressure. 2018.

[3] NEUSSER, H.J. et al. Volkswagen's new modular TDI generation. 33rd Vienna Motor Symposium. 2012.

[4] SOLTIC, P., HILFIKER, T., HUTTER, R., HÄNGGI, S. Experimental comparison of efficiency and emission levels

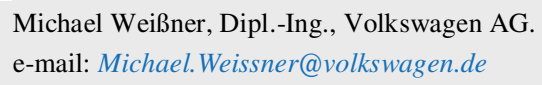

e-mail: Martin.Schuettenhelm@volkswagen.de

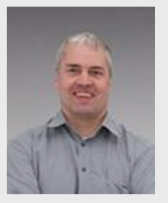

Frank Beger, Dipl.-Ing., Volkswagen AG.

e-mail: Frank.Beger@volkswagen.de

Gunesh Tallu, M.Sc., Volkswagen AG

e-mail: Gunesh.Tallu@volkswagen.de 